\title{
MIR376C Pre-miRNA
}

National Cancer Institute

\section{Source}

National Cancer Institute. MIR376C Pre-miRNA. NCI Thesaurus. Code C96012.

MIR376C pre-miRNA (86 bases) is encoded by the human MIR376C gene. This nucleic acid is involved in the modulation of target gene transcription or mRNA translation. 